ESPECIAL

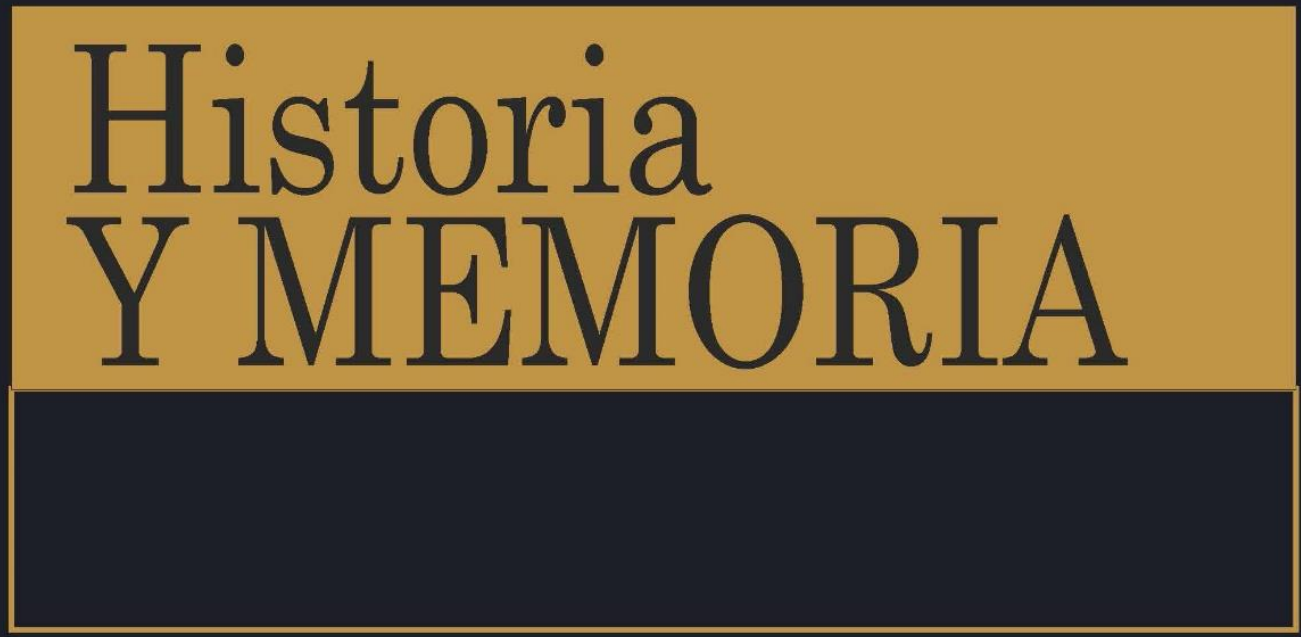

ISSN: 2027-5137 Número Especial • 10 Años • Año 2020 - Tunja, Colombia

La junta central de higiene de Colombia, otra de las víctimas de la pandemia de gripa de 1918-1919

https://doi.org/10.19053/20275137.nespecial.2020.11592

Abel Fernando Martínez Martín Bernardo Francisco Meléndez Álvarez Edwar Javier Manrique Corredor Páginas 349-387

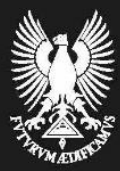




\title{
La junta central de higiene de Colombia, otra de las víctimas de la pandemia de gripa de 1918-1919*
}

\author{
Abel Fernando Martínez Martín ${ }^{1}$ \\ Bernardo Francisco Meléndez Álvarez ${ }^{2}$ \\ Edwar Javier Manrique Corredor ${ }^{3}$ \\ Grupo de Investigación Historia de la Salud en Boyacá \\ Universidad Pedagógica y Tecnológica de Colombia
}

https:/doi.org/10.19053/20275137.nespecial.2020.11592

La revista Historia \& MEMORIA de la Universidad Pedagógica y Tecnológica de Colombia en Tunja, me ha encargado esta presentación del artículo titulado: «La Junta Central de Higiene de Colombia, otra de las víctimas de la Pandemia de Gripa de 1918-1919»", reimpreso por la revista a propósito de la excepcional situación de la pandemia por el Coronavirus SARS CoV-2 causante de la COVID-19.

\footnotetext{
* El artículo fue publicado originalmente en la revista Astrolabio, Nueva Época $\mathrm{n}^{\circ} 13$ de 2014 https://revistas.unc.edu.ar/index.php/astrolabio/article/view/8672 (acceso abierto, bajo bajo Licencia Creative Commons Atribución-NoComercialCompartirIgual 4.0 Internacional, https://creativecommons.org/licenses/by-ncsa/4.0/) El artículo no fue modificado del original.

1 Doctor en Historia. Docente del programa de Medicina de la Universidad Pedagógica y Tecnológica de Colombia. Director del Grupo de Investigación Historia de la Salud en Boyacá-UPTC. Director del Museo de Historia de la Medicina y la Salud-Uptc. $\bowtie$ abel.martinez@uptc.edu.co @ https://orcid.org/0000-0002-4621-6072.

2 Magíster en Educación Virtual. Magíster en Investigación en Atención Primaria en Salud. Docente del programa de Medicina de la Universidad Pedagógica y Tecnológica de Colombia.凶bernardo.melendez@uptc.edu.co (1) https://orcid.org/00000002-7277-5062.

3 Máster Universitario en Investigación en Atención Primaria. Docente del programa de Medicina de la Universidad Pedagógica y Tecnológica de Colombia. Investigador del Grupo Historia de la Salud en Boyacá- UPTC. $\bowtie$ edwar.manrique@ uptc.edu.co (1) https://orcid.org/0000-0003-3916-6166.

4 «La junta central de higiene de Colombia, otra de las víctimas de la pandemia de gripa de 1918-1919,» Astrolabio, Nueva Época, n 13 (2014): 5-37, https://revistas. unc.edu.ar/index.php/astrolabio/article/view/8672.
} 
Creo pertinente recordar la clasificación de las etapas de una epidemia realizada por el historiador de la medicina Charles E. Rosenberg en su trabajo sobre el VIH-SIDA que puede servirnos en estos tiempos extraños: Acto 1. La revelación progresiva. La aceptación que una epidemia ha trastocado nuestra cotidianidad; Acto 2. Manejando el azar. Aquel marco de referencia que nos permita entender el curso de la epidemia y racionalizar lo que está sucediendo desde el conocimiento legitimado socialmente; Acto 3. Negociando una respuesta pública. Aquellas acciones colectivas que definen si es posible controlarla o no.

Las epidemias y la incertidumbre han estado ligadas a lo largo de la historia, en la incógnita plaga de Atenas, en la medieval peste negra en Milán, en las desoladas islas del Caribe, entre las ruinas de México-Tenochtitlan, de Quito al Cusco en la crisis dinástica de los Incas, en los caminos de la celestial medicina de Chiquinquirá a Tunja, tras las murallas de Cartagena de Indias y en aquel lluvioso noviembre de 1918 en Bogotá.

Esta última crisis por la pandemia de Gripa a inicios del siglo XX en la capital de Colombia es la que nos convoca. Retratada por los autores (Martínez, Meléndez y Manrique) del Grupo de Historia de la Salud en Boyacá de la UPTC, grupo que desde hace 15 años ha investigado y publicado, desde Tunja, uno de los trabajos más completos sobre este tema en el país y la región, no solo por las series demográficas, sino por el análisis sociocultural planteado. En el caso de Bogotá, las instituciones de Higiene Pública, o quizá sea mejor hablar de Asistencia Social -beneficencia o caridad- en 1918, fueron víctimas también de la enfermedad. La iniciativa privada que lideró la respuesta, la Junta de Socorros superó en actividad a la oficial Junta Central de Higiene, sobrepasada ampliamente en medio de las precarias condiciones de saneamiento de la ciudad. En 1918 la higiene dejó de ser un discurso más de los congresos médicos nacionales y paso a manifestarse en las obras urbanas. 
La presión cultural y biológica a las que una epidemia nos somete como especie y estructura social produce cambios que no se circunscriben solamente a los campos del saber médico o biológico, sino que se reflejan en insospechados rincones de nuestra vida que pueden convertirse en historia. A través del tiempo, si algo tienen en común todas las epidemias o pandemias, es el miedo y la incertidumbre que traen, ya sea en el siglo XVI, en el XX o en el XXI.

\section{Andrés Ricardo Otálora Cascante \\ Doctor en Historia}

\section{Resumen}

Objetivo: El presente artículo, a través de las fuentes primarias, busca establecer el papel del Estado y las medidas tomadas ante la aparición de la pandemia de gripa de 1918 en Bogotá. Materiales y métodos: Se consultaron como fuentes primarias los periódicos que circulaban en Bogotá y Colombia durante 1918, los informes oficiales de la Junta Central de Higiene y de la Junta de Socorros y las tesis de medicina de la Universidad Nacional de Colombia, además de hacer una revisión de las fuentes secundarias sobre el tema. Conclusión: La Higiene Pública, en manos del Estado, se mostró incapaz de hacer frente a la pandemia, siendo la Junta de Socorros, un organismo privado constituido por los notables de la capital, la única institución que realizó acciones efectivas con los afectados. Esta institución aparece recordada y alabada por los medios escritos, en contraposición a la Dirección Nacional y Municipal de Higiene, que fueron fuertemente criticadas por su escasa intervención ante la pandemia y representadas como víctimas en las caricaturas.

Palabras clave: gripa 1918, pandemia, Bogotá, Junta de Socorros, Junta Central de Higiene. 


\title{
The Colombian central board of hygiene, another victim of pandemic flu 1918-1919
}

\begin{abstract}
Objective: In this paper, through primary sources, we intend to clarify and specify the role and actions taken by the government against the flu pandemic of 1918 in Bogotá. Materials and methods: Primary Sources: Newspapers of the time in Bogota and Colombia, official reports of the Central Board of Hygiene, official reports of the Board of Relief and medical thesis, National University of Colombia. Also, secondary sources on the topic were reviewed. Conclusion: The Public Hygiene, headed by State, proved unable to deal with the pandemic. The Relief Board was the only institution that took effective action. This institution of private character was created by the notables of the capital. The Board of Relief is remembered and praised by the print media, in contrast, the Central Board of Hygiene was represented as victim in the cartoons and was heavily criticized for their limited participation in the pandemic flu.
\end{abstract}

Key Words: flu 1918, pandemic, Bogota, Board Relief, Central Board of Hygiene.

\section{Le comité central d'hygiène de Colombie: une autre victime de la pandémie de grippe de 1918-1919}

\section{Résumé}

Objectif: Cet article vise à établir le rôle de l'État colombien et les mesures qu'il a adopté face à la pandémie de grippe de 1918 à Bogotá. Sources et méthodes: Outre les sources secondaires sur le sujet, on a consulté des sources primaires tels que les journaux qui circulaient et à Bogotá et en Colombie pendant 1918, les rapports officiaux du Comité Central d'hygiène et du Comité de Secours, ainsi que les thèses de médicine soutenues à l'Université Nationale de Colombie. Conclusion: Étant donné que l'hygiène publique contrôlée par l'État colombien s'est avérée inefficace pour faire face à la 
pandémie, c'est une institution privée, le Comité de Secours, constitué par les nobles de la capitale, la seule entité ayant été réalisée des actions effectives au bénéfice des malades. D'où que cette institution soit si souvent mise en valeur dans les documents écrits de l'époque, contrairement à ce qui arrive avec la Direction Nationale et Municipale d'hygiène, très sévèrement critiquées par son intervention quasiment nulle devant la pandémie et de ce fait représentées comme étant elles-mêmes des victimes de la maladie.

Mots-clés: grippe de 1918, pandémie, Bogotá, Comité de Secours, Comité Central d'hygiène.

«Lo mejor es aguardar la gripa ${ }^{5} \mathrm{y}$, si viene, cuidarla con el mayor esmero», Dr. Manuel Narciso Lobo. Presidente de la Junta Central de Higiene. ${ }^{6}$

\section{Colombia en 1918 sigue en el siglo XIX}

El territorio colombiano, con una extensión de 1.148.748 Km2, estaba en el año 1918 prácticamente deshabitado, ya que el $75 \%$ del país estaba conformado por terrenos baldíos. Colombia era un país completamente rural, en donde los tres ramales de la cordillera de los Andes determinan la incomunicación de las cinco regiones geográficas que la componen, zonas que se comunicaban mediante recuas de mulas, el transporte fluvial por el río Magdalena, y los escasos $1500 \mathrm{~km}$. de vías férreas, que hacían del país un territorio desintegrado en lo interno y aislado en lo externo; $;^{7}$ un país que aún no salía del siglo XIX, en manos de una élite católica andina, que se percibía como culta y como blanca, y que pensaba que el país no podía

\footnotetext{
5 En Colombia se utilizó en 1918 -y se sigue utilizando hoy-el término gripa, derivado del término original francés grippe, término que utilizaremos en el curso de este texto histórico. Los anglosajones prefieren la raíz latina influenza, flu, que originalmente se refería a la influencia de los astros sobre la salud humana.

6 «La Gripa. Habla el Presidente de la Junta Central de Higiene», El Nuevo Tiempo, Bogotá, 22 de octubre de $1918^{\mathrm{a}}, 1$.

7 Mauricio Archila, Cultura e identidad obrera. Colombia 1910-1945 (Bogotá: CINEP, 1991).
} 
progresar porque el pueblo no era como ellos. ${ }^{8}$ La Degeneración de la $R a z a^{9}$ y la ubicación tropical, tampoco eran apropiadas para poder alcanzar el anhelado progreso y la civilización, como lo habían logrado Europa y Estados Unidos, referentes permanentes de las élites colombianas.

La sociedad estaba hegemonizada por los hacendados en el plano económico y social, controlada políticamente por el Partido Conservador, e ideológica y culturalmente por el clero católico. Las pésimas condiciones de salud y asistencia social, la pobreza y una desastrosa situación higiénica eran la nota dominante en las primeras décadas del siglo XX, que se agravaba por la inexistencia o muy baja cobertura de los servicios públicos. La esperanza de vida de un colombiano, en 1920, era de solo 33 años ${ }^{10}$, y lo más probable es que fuera analfabeto, pues: "desertaba el $98 \%$ de los niños que comenzaban la educación primaria en las ciudades y en las escuelas rurales solo se enseñaba hasta el tercer grado». ${ }^{11}$ Solo las clases acomodadas se podían permitir el acceso a la educación secundaria.

Mientras las potencias mundiales se enfrascaban en la Primera Guerra, que causó menos víctimas que la pandemia de gripa de 1918-1919, donde se combatía por el control de colonias y mercados, en Colombia, el conflicto ocasionó la suspensión de los flujos comerciales y financieros y de las obras públicas, causando desempleo. El gobierno sufrió un déficit teniendo que acudir a préstamos. Fuertes oscilaciones cambiarias y la intensa especulación crearon pánico financiero en el país ${ }^{12}$, en el momento de afrontar la pandemia de gripa.

8 Jorge Orlando Melo, «La idea del progreso en el siglo XIX, ilusiones y desencantos, 1780-1930» (XVI Congreso de colombianistas, Charlottesville, 6 de agosto de 2008).

9 El psiquiatra Miguel Jiménez López, siguiendo la Teoría de la Degeneración del alienista francés B. A. Morel, reintroduce en Colombia la Teoría de la Degeneración de la Raza, en la cátedra inaugural de Patología Mental, en la Facultad de Medicina de la Universidad Nacional, en 1916.

10 Renán Vega Cantor, Gente muy rebelde. Enclaves, transportes y protestas obreras (Bogotá: Pensamiento Crítico, 2000).

11 Marco Palacios, Entre la legitimidad y la violencia. Colombia 1875- 1994 (Bogotá: Editorial Norma, 2003).

12 Patricia Londoño y Santiago Londoño, «Vida diaria en las ciudades colombianas,» en Nueva Historia de Colombia, dir. Álvaro Tirado (Bogotá: Planeta Colombiana, 


\section{La vergonzosa y cambiante organización de la higiene a inicios del siglo $\mathrm{XX}$}

«Es una vergüenza para la república que, a estas horas del siglo XX, cuando se apresta a conmemorar la más grandiosa epopeya de su libertad, no ha expedido una ley orgánica de la higiene pública, la cual es indispensable y urgente» ${ }^{13}$.

En las primeras décadas del siglo XX la atención de los problemas de salud en Colombia estaba fragmentada en diferentes tipos de respuestas sociales, tres tipos de política social, que venían forjándose desde el siglo XIX. En primer lugar, la beneficencia pública, que se dirige a los pobres y se fundamenta en la caridad cristiana con algunos auxilios estatales. En segundo lugar, el ejercicio privado de la práctica médica, escaso y solo accesible en las ciudades a las clases acomodadas. Y, por último, la higiene pública dedicada a la sanidad portuaria, el control de alimentos, el aislamiento de los leprosos y el control de las epidemias ${ }^{14}$.

Tras la Constitución centralista de 1886, se organizó por vez primera la sanidad pública en Colombia, como una rama del gobierno nacional; y por Ley 30, de ese mismo año, se creó un cuerpo colegiado, asesor del gobierno central en las decisiones relacionadas con la higiene, que se denominó Junta Central de Higiene, compuesta por tres médicos y un secretario, adscrita al Ministerio de Fomento ${ }^{15}$. La Ley establecía también la creación de las Direcciones Departamentales de Higiene, aunque estas solo funcionaron hasta la segunda década del siglo $\mathrm{XX}^{16}$.

La Junta Central de Higiene se ocupó de las enfermedades epidémicas, del saneamiento y del control

\footnotetext{
1989), 318-337.

13 Cenón Solano, Organización de la higiene Pública (Bogotá: Imprenta de El Siglo, 1918), 4.

14 Mario Hernández Álvarez, La salud fragmentada en Colombia, 1910-1946 (Bogotá: Instituto de Salud Pública, Universidad Nacional de Colombia, 2002).

15 Ley 30/ 1886, del 20 de octubre, por el que se crea Juntas de Higiene en la Capital de la República y en las de los Departamentos y Ciudades principales.

16 Álvarez, La salud fragmentada en Colombia, 1910-1946.
} 
de puertos, bajo la presión de las Convenciones Sanitarias Internacionales firmadas por Colombia. La Ley 30 ordenaba que las disposiciones de la Junta de Higiene tuvieran fuerza de obligatoriedad y fueran respaldadas por las autoridades. La Junta Central de Higiene no manejaba presupuesto ni tenía fuero para hacer cumplir las normas que dictaba. Tampoco se ocupaba de las instituciones de salud como hospitales, asilos u hospicios, que estaban a cargo de las juntas de beneficencia. Su actividad no estuvo destinada a promover grandes transformaciones higiénicas, sino a una modesta pero constante regulación de aspectos particulares que fueron puestos a su consideración ${ }^{17}$.

Sorprende ver cómo la dirección de Salud en Colombia cambia constantemente de denominación y, sobre todo, de Ministerio: del Ministerio de Fomento donde nació, la Junta Central de Higiene, cambiando de nombre, pasó al Ministerio de Gobierno, para irse luego al de Agricultura y Comercio y terminar en el Ministerio de Instrucción Pública, dependiendo si el interés del país estaba en los puertos y su relación con el comercio internacional o en la agricultura, en medio de la bonanza cafetera que impulsaba el desarrollo colombiano, o en el de Instrucción pública, si el interés estaba en difundir la Higiene por medio de la educación.

La Ley 33, de 1913, convirtió a la Junta Central de Higiene en Consejo Superior de Sanidad, organismo que era dependiente del Ministerio de Gobierno y estaba compuesto por 5 miembros: tres profesores médicos, un profesor de Ciencias Naturales y un bacteriólogo - en concordancia con las mentalidades higiénica y etiopatológica-con asesoría directa de la Academia Nacional de Medicina. La Ley 33 establecía las Juntas Departamentales de Higiene, formadas por tres médicos graduados, Juntas de Salubridad y Comisiones Sanitarias municipales ${ }^{18}$.

17 Emilio Quevedo Vélez y otros, Café y gusanos, mosquitos y petróleo: el tránsito desde la higiene hacia la medicina tropical y la salud pública en Colombia, 1873-1953 (Bogotá: Universidad Nacional de Colombia, 2004).

18 Pablo García Medina, «La Organización Sanitaria en Colombia,» Boletín de la Oficina Sanitaria Panamericana, 6 (2) (1927): 3-14. 
Tan solo un año después, la Ley 84 de 1914, mediante la que se dictan algunas disposiciones sobre extinción de la langosta y sobre higiene pública y privada, retornó nuevamente a la Junta Central de Higiene, por motivos económicos, ya que la ley anterior tenía el defecto de exigir numeroso personal y de imponer mayores gastos a la nación, a los departamentos y a los municipios, en un momento de estrechez presupuestal ${ }^{19}$. Los objetivos principales de la Junta Central de Higiene eran el control de los puertos exigido por las «Convenciones Sanitarias Internacionales que obligan a la Nación»; la conservación de la vacuna de la viruela y la creación de un Instituto Bacteriológico Central, ente que quedaba encargado de resolver las consultas de la Junta Central de Higiene y ejecutar trabajos bacteriológicos para el estudio de las enfermedades endémicas y epidémicas del país ${ }^{20}$.

El artículo noveno de la Ley 84 de 1914, con respecto al control de enfermedades infecciosas que tuvieran carácter epidémico, establecía la responsabilidad de la Nación ante las epidemias:

Cuando una enfermedad infecciosa grave amenace tomar el carácter de epidemia en toda la República o en una parte considerable de su territorio y se reconozca que los recursos para la defensa local sean insuficientes, serán de cargo de la Nación los gastos que ocasionen las medidas que dicten las autoridades sanitarias, quienes deben someter a la aprobación del Gobierno Nacional los presupuestos para tales gastos ${ }^{21}$.

Durante la Pandemia de Gripa de 1918-1919, aunque esta era la legislación vigente, se evidencia que quien asumió finalmente la responsabilidad financiera en las leyes y resoluciones fue, un organismo privado, la Junta de Socorros, la que canalizó los recursos económicos, mediante la caridad, y

19 Quevedo Vélez y otros, Café y gusanos, mosquitos y petróleo.

20 Ley 84/1914, por la cual se dictan algunas disposiciones sobre extinción de la langosta y sobre higiene pública y privada.

21 Ley 84/1914, 1. 
los recursos humanos, mediante la solidaridad, para enfrentar la elevada morbi-mortalidad causada por la epidemia de gripa.

La Ley 32 del 29 de octubre de 1918 que, como veremos más adelante, fue expedida en plena pandemia de gripa, reemplazó la Junta Central de Higiene por otra oficina llamada Dirección Nacional de Higiene, y la organización estatal de salud pasó a depender del Ministerio de Agricultura y Comercio y, posteriormente, del Ministerio de Instrucción Pública. La Dirección Nacional conservó la misma estructura administrativa con la que venía funcionando la Junta Central de Higiene, pero responsabilizó a los departamentos de los gastos; esta organización solo se hizo efectiva desde el 1 de enero de 1919, ya finalizada la pandemia de gripa ${ }^{22}$. La Dirección Nacional de Higiene estuvo regida por el médico higienista Pablo García Medina, quien fuera el principal protagonista del proceso de organización sanitaria de Colombia a principios del siglo XX. Sólo hasta la cuarta década de este siglo, se crearía el Ministerio de Higiene y el Seguro Social, dando mayor responsabilidad estatal a la problemática de salud pública en Colombia.

\section{Bogotá sin higiene, está condenada a morir}

La ciudad de Bogotá, ubicada en los Andes orientales a 2600 metros sobre el nivel del mar, con una temperatura media de $14^{\circ} \mathrm{C}$, ha sido la capital del país desde el Nuevo Reino de Granada, en el siglo XVI, cuando se llamaba Santafé. La ciudad pasó de una baja densidad de población, a principios del siglo XIX, a una extrema concentración de población en $1881^{23}$, presentando un crecimiento poblacional acelerado, a causa de la migración del campo hacia la ciudad y una incipiente urbanización, aumentando en espacio 1,6 veces y quintuplicando su población ${ }^{24}$. El censo de 1918, realizado meses antes de la pandemia de gripa, muestra una población

22 Pablo García Medina, «Informe del Director Nacional de Higiene al Ministro de Instrucción Pública,» Revista de Higiene, 9 (115) (1919): 279-310. Quevedo Vélez y otros, Café y gusanos, mosquitos y petróleo.

23 Germán Mejía Pavony, «Los itinerarios de la transformación urbana. Bogotá, 1820-1910,» Anuario Colombiano de Historia Social y de la Cultura, 24 (1997): 101137.

24 El crecimiento de población en Colombia fue de 41.3\% para 1918 con respecto a 1905. Ver: Carmen Elisa Flórez, Las transformaciones socio-demográficas en Colombia durante el siglo XX (Bogotá: Banco de la República y Tercer Mundo Editores, 2000). 
de 141.639 habitantes para Bogotá, de los cuales el $42 \%$, casi 60.000 , vivían en los barrios altos, en arrabales asentados sobre las faldas de los cerros de Guadalupe y Monserrate ubicados al oriente de la ciudad ${ }^{25}$.

La zona alta de la ciudad, conocida como el Paseo Bolívar, estaba ocupada por la población más pobre y fue la más afectada por la epidemia. Los antiguos arrabales se fueron llenando con los flujos migratorios. Sus barrios densamente poblados, que presentaban las peores condiciones sanitarias, con total ausencia de servicios públicos, compartiendo el hacinamiento con los animales, aparecen descritos en las tesis de grado de doctorado en medicina de la Universidad Nacional como el espacio de la miseria, el desaseo, los miasmas, la enfermedad, la inmundicia, los vicios y la inmoralidad de la ciudad. Tugurios de ranchos de paja y calles llenas de barro y basura, que acogían a:

la clase más necesitada y el lugar más desaseado de la capital, en donde es muy bajo el nivel moral de las gentes que allí sufren los rigores de la más espantosa miseria (...) los enfermos se aglomeran en covachas inmundas que son generalmente dormitorio, cocina y establo de animales domésticos ${ }^{26}$.

Para la prensa capitalina, el Paseo Bolívar, en donde se asentaban la mayoría de barrios obreros de la ciudad ${ }^{27}$ :

con sus chicherías nauseabundas, sus casuchas asquerosas y sus suburbios donde hierve el crimen, la inmoralidad y el vicio, es el perpetuo proveedor de miasmas y escándalos para la capital de la república; teniendo todavía abiertas las infectas bocas de multitud de alcantarillas. De suerte que familias enteras que con gatos y perros viven en estos cuartos, arrojan a la vía pública, o a la alcantarilla de la esquina, todas sus inmundicias ${ }^{28}$. escribe el cronista del periódico capitalino Sur América.

$25 \quad$ El Tiempo, Bogotá, 22 de noviembre de 1918d.

26 Enrique Castilla, Historia de la gripa en Colombia. Tesis doctoral (Bogotá: Tipografía Ideal, 1922), 23.

27 En 1920, de los 18 barrios obreros de Bogotá, 13, sin servicios públicos, estaban en el Paseo Bolívar.

28 Sur América, Bogotá, 26 de octubre de $1918^{\mathrm{a}}, 1$. 
La insalubridad de la capital es frecuentemente reseñada en las tesis, los periódicos y en las revistas: "se carece de lo más indispensable en asuntos higiénicos, y cualquier localidad de cuarto orden del extranjero se encuentra mejor preparada para contrarrestar las calamidades públicas» ${ }^{29}$.

Definitivamente, para los periodistas Bogotá, en 1918, no era ningún paraíso:

Los servicios de aseo, de aguas, de alcantarillado, de hospitales, de cementerios, y de todo otro género, no pueden ser calificados siquiera de pésimos, por la circunstancia de que no existen. Autoridades sin aptitudes, habitantes sin espíritu público, tesoro municipal misérrimo, de Bogotá no cabe decir que es un paraíso, sino por cuanto tuvo aquel lugar de primitivo, y de malsano ${ }^{30}$.

Esto escribía Armando Solano en El Gráfico, periódico que describe a Bogotá en 1918 como: «ciudad sin avenidas, sin parques, sin redes capaces para el alcantarillado, sin cuerpo de bomberos (...) sin agua, sin higiene, está condenada a morir» ${ }^{31}$. Bogotá no contaba con la infraestructura necesaria para ofrecer servicios de asistencia pública. La atención de los enfermos pobres estaba en manos de la caridad pública, a cargo de comunidades religiosas ${ }^{32}$. El informe de la Junta de Socorros, de diciembre de 1918, consigna en Bogotá la:

[...] falta absoluta de organización alguna que remplace siquiera en parte, el servicio de asistencia pública, tal como se encuentra organizado en los países más civilizados; la triste insipiencia de nuestra higiene pública merced a la cual pueden reputarse como un milagro la existencia normal de la ciudad, con sus calles llenas de lodo o de polvo (...) y sobre todo esto, la miseria y el supremo desaseo en que viven las clases bajas del obrerismo ${ }^{33}$.

29 Cromos, Bogotá, 16 de octubre de 1918a, 2.

30 El Gráfico, Bogotá, 19 de octubre de 1918b, 2.

31 El Gráfico, Bogotá, 6 de julio de 1918a,3.

32 La atención a los enfermos pobres estaba en manos de la caridad pública, a cargo de comunidades religiosas auxiliadas por grupos de élite de interés social que actuaban por medio de las juntas de beneficencia (Noguera, 2003).

33 Eduardo Carvajal, Exposición de la Junta de Socorros. Bogotá. Arboleda y Valencia. Museo de Historia de la Medicina y la Salud (Tunja: Universidad Pedagógica 


\section{El Presidente calla, la organización sanitaria estatal no se siente, la privada Junta de Socorros y la caridad asumen la crisis}

«Lo alarmante de la situación en la clase popular, en la cual hubo el mayor número de defunciones por falta de recursos, hizo que se organizara rápidamente una Junta de Socorros, la cual fundó hospitales, repartió víveres, medicinas, etc.» ${ }^{34}$.

El Presidente de la República, el conservador antioqueño Marco Fidel Suárez, quien había tomado posesión del cargo dos meses atrás del inicio de la pandemia de gripa, en agosto de 1918, es criticado en los medios impresos, por la falta de acción y el mutismo frente a la pandemia, que contrasta con los esfuerzos de la élite bogotana por poner fin a la misma ${ }^{35}$. El 17 de octubre de 1918, la misma prensa capitalina, da cuenta del fallecimiento en Estados Unidos, a causa de la pandemia de gripa, del joven Gabriel Suárez Orrantia, hijo de Marco Fidel Suárez, Presidente de la República, quien se encontraba en Pittsburg, perfeccionando sus estudios en mecánica ${ }^{36}$.

El Heraldo de la Costa, diario de la ciudad puerto sobre el Caribe de Barranquilla, le da el nombre de: «El abrazo de Suárez» a la letal pandemia de gripa que llega al país por sus puertos, noticia que se caricaturiza en el semanario El Cómico, en Bogotá, colocándole debajo de la ilustración las siguientes rimas, que relacionan la epidemia que llega con las recientes elecciones, que dividieron al gobernante Partido Conservador (ver figura 1).

«A esta epidemia, mal fiero

Que causó tantos pesares

$\mathrm{Y}$ tanto dolor sincero

Un diario barranquillero Llama

"el abrazo de Suárez"

y Tecnológica de Colombia, 1918), 7.

34 Jorge Laverde, Contribución al estudio de la epidemia de Gripe, en Bogotá, en 1918. Tesis doctoral (Bogotá: Tipografía Artística, 1918), 19.

35 Gaceta Republicana, Bogotá, 30 de octubre de 1918c.

36 Cromos, Bogotá, 26 de octubre de 1918b. El Diario Nacional, Bogotá, 17 de octubre de 1918a. 
Y a Bogotá el mal trató

Con dureza, por razones

Que muy bien me explico yo:

Porque el pueblo le negó

su voto en las elecciones».

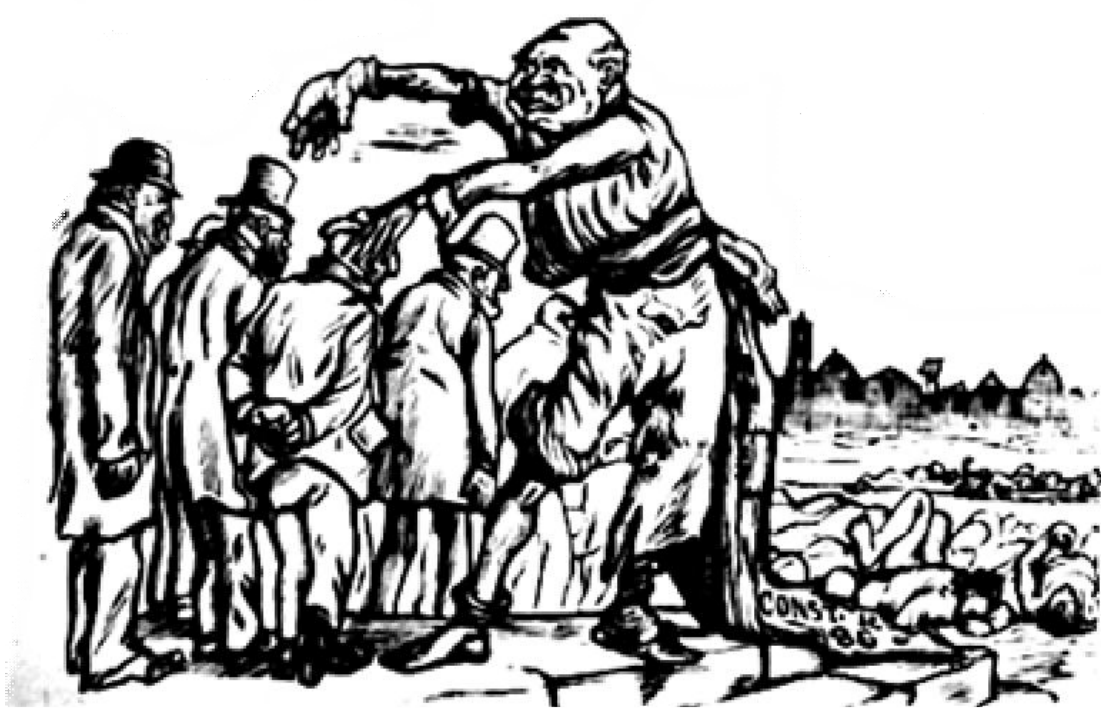

Figura 1. Caricatura «El abrazo de Suárez», nombre que le da un periódico del puerto atlántico de Barranquilla a la pandemia de gripa de 1918, cuando llega a Colombia

Fuente: «El abrazo de Suárez», Bogotá Cómico, Bogotá, octubre de 1918a.

En la oficial Revista de Higiene de 1919, el doctor Pablo García Medina, nuevo Director Nacional de Higiene, publica el informe que le presenta al Ministerio de Instrucción Pública, donde consigna que la gripa apareció en la ciudad de Bogotá en los primeros días del mes de octubre y se «generalizó desde el 20 de octubre tan rápidamente, que el 25 se calculaba, con fundamento, el número de griposos pasaba de cuarenta mil. La mortalidad fue entonces muy alta ${ }^{37}$. Los muertos en la capital colombiana se triplicaron en un periodo de tan solo dos días. Del 20 al 21 de octubre de 1918, se registraba que: «el

37 García Medina, «Informe del Director Nacional de Higiene al Ministro de Instrucción Pública,» 279-80. 
promedio de la mortalidad en Bogotá era de algo más de 300 personas por mes. Ahora ha sido de más de 500 a la semana ${ }^{38}$.

En medio del pánico, la lluvia y el frío, Bogotá entró en crisis. En su tesis de doctorado el médico Jorge Laverde afirma:

Las oficinas públicas, los colegios, la universidad, las chicherías, los teatros y las iglesias estaban vacías; los servicios urbanos se colapsaron; la policía, el tranvía, el tren y los correos se paralizaron, porque la mayoría de policías, operarios, curas, alumnos, profesores y empleados enfermaron: se suspendieron todos los espectáculos públicos, y las calles de la ciudad, especialmente en la noche estaban casi desiertas ${ }^{39}$.

El 16 de octubre escribía el cronista de la Revista Cromos, que cubría la mortal pandemia: «Doloroso resulta saber que gente pobre muere como moscas. Bien por aquellos que tienen un lecho que los ampare, que infelices hubo que murieron en la calle como mueren los perros» ${ }^{40}$.

Las críticas de la prensa bogotana por la falta de acción estatal ante la situación de muerte y de contagio, que ocasiona la pandemia de gripa, se hacían, día a día, más frecuentes y, cada vez, más numerosas:

La acción de las autoridades encargadas de velar por la pública salubridad no se ha hecho sentir. Hasta ahora la Junta de Higiene no ha tomado providencia alguna. Esa inercia es inexplicable y muy mal sentado quedaría el nombre de esa entidad si no trata a la medida de sus fuerzas de combatir el flagelo ${ }^{41}$.

La primera acción de una autoridad estatal frente a la pandemia fue la convocatoria que Eduardo Restrepo Sáenz,

38 Sur América. Bogotá, 29 de octubre de 1918b, 1.

39 Laverde, Contribución al estudio de la epidemia de Gripe, en Bogotá, en 1918.

Tesis doctoral, 18.

40 Cromos, Bogotá, 16 de octubre de $1918^{\mathrm{a}}, 157$.

41 Gil Blas, Bogotá, 21 de octubre de 1918, 1. 
como recién posesionado Gobernador de Cundinamarca, ${ }^{42}$ hace a la Junta Central de Higiene, con carácter de urgente, convocatoria que se publica en el diario El Tiempo y en el periódico Gil Blas, que dice:

\begin{abstract}
Como responsable de la situación de salud de Cundinamarca de acuerdo a la Ley 84 de 1914, que establece que la Junta Central de Higiene desempeñará las funciones de Junta Departamental en Cundinamarca (...) como ha llegado a ser alarmante la epidemia (...) en mi carácter de Jefe de la Administración pública departamental y ya que esa honorable Junta por virtud del Parágrafo $1^{\circ}$ de la Ley 84 de 1914 tiene las funciones correspondientes al Director Departamental de Higiene, me permito por el digno conducto de usted, convocar a una reunión extraordinaria en el local de la Gobernación, con el fin de acordar las providencias necesarias sobre este grave asunto ${ }^{43}$.
\end{abstract}

La pandemia había golpeado ya a la débil organización burocrática y sanitaria colombiana, antes de poder concretar cualquier acción para tratar de detenerla. La prensa registra la muerte del senador Antonio Regino Blanco «a causa de la violenta epidemia de gripa», el 21 de octubre ${ }^{44}$. El mismo día, un periodista del diario el Nuevo Tiempo, visitó las oficinas de la Junta Central de Higiene encontrando: «que tanto los señores médicos como los empleados de la oficina están enfermos a causa de la gripa». Agrega el reportero, que el Presidente de la Junta Central de Higiene, el doctor Manuel Narciso Lobo: «me recibió amablemente en su casa, y me dictó las siguiente cuartilla de palpitante actualidad $»^{45}$.

El Doctor Lobo reconoce en su «dictado» al periodista, el carácter pandémico de la gripa «que se extiende con una velocidad igual a la de los más rápidos trenes» y recomienda esperarla y cuidarla en caso de que llegue: «lo mejor es aguardar la gripa y, si viene, cuidarla con el mayor esmero»; también afirma el Presidente de la Junta Central de Higiene su

42 Eduardo Restrepo Sáenz, se posesiona como Gobernador de Cundinamarca el 30 de septiembre de 1918 (El Tiempo, 1918b).

43 Gil Blas, Bogotá, 21 de octubre de 1918, 1.

44 La Linterna, Tunja, 25 de octubre de 1918, 1.

45 El Nuevo Tiempo. Bogotá, 3 de noviembre de 1918d, 1. 
posición anti- miasmática, al afirmar que: «no hay fundamento científico para creer que las emanaciones de las alcantarillas sean la causa de la enfermedad», como lo afirmaba el director de la Oficina de Higiene y Salubridad de Bogotá, el doctor Cenón Solano, quien sostenía: «que el mal que ahora se da en la capital, proviene del cambio que se hizo a los sifones de las alcantarillas» ${ }^{46}$. Afirmando, además, que las troneras con tapa de lata son incapaces de impedir que los gases de las cloacas no se comuniquen con la atmósfera de la ciudad ${ }^{47}$.

El Doctor Manuel Narciso Lobo, también le recuerda al periodista del Nuevo Tiempo, que cuando, años atrás, ejerció la profesión en el Departamento de Norte de Santander, en el municipio de El Carmen, que tenía una población de 4000 habitantes, ante una epidemia similar de gripa: "aconsejé entonces el aseo general de la población y dormir con puertas y ventanas abiertas», consejo, que dado el frío y las lluvias que atacaban en medio de la gripa a la población de Bogotá, el médico Presidente de la Junta Central de Higiene, advierte que esta medida: "no sería prudente en Bogotá»" ${ }^{48}$.

Sorprende la actitud del agripado Presidente de la Junta Central de Higiene, máximo organismo de Salud de Colombia, recomendando frente a la situación de pánico y mortalidad que estaba causando la pandemia de gripa en Bogotá, simplemente: «aguardarla» y «cuidarla con esmero». También sorprende la explicación miasmática que comparte la prensa capitalina, y que sostiene el director de la Oficina Municipal de Higiene, el médico y gran crítico de la Junta Central, Cenón Solano, terminándose la segunda década del siglo XX.

Se evidencia también en la prensa capitalina la disputa entre el Director de Higiene y Salubridad Municipal de Bogotá el médico Cenón Solano y el Presidente de la Junta Central Higiene, Manuel Narciso Lobo, quien había sido el anterior Director Municipal de Higiene. Esta disputa está condensada

46 El Nuevo Tiempo. Bogotá, 3 de noviembre de 1918d, 1.

47 Gaceta Republicana, Bogotá, 19 de octubre de $1918^{\text {a }}, 1$.

48 El Nuevo Tiempo. Bogotá, 3 de noviembre de 1918d, 1. 
en la publicación que hace el doctor Cenón Solano, en octubre de 1918, en plena pandemia, que va dirigida al Congreso y a Marco Fidel Suárez, Presidente de la República. Así se refiere Solano, de forma contundente y crítica, en su publicación Organización de la Higiene Pública:

La Junta Central de Higiene, donde es natural que estén los más sabios de nuestros higienistas ha sido incapaz para sospechar el origen de nuestras calamidades provenientes de falta de higiene pública; ha sido incapaz de elaborar el primer reglamento sanitario sobre asuntos que le competen, y los pocos acuerdos que ha expedido no están fundamentados sobre bases científicas (...) ¿Cómo el Gobierno consiente que la Junta Central de Higiene nos exhiba ante el mundo como país salvaje e imbécil? ${ }^{49}$.

En comunicación del 23 de octubre de 1918, el doctor Manuel Narciso Lobo, Presidente de la Junta Central de Higiene, comunica las medidas de profilaxis individual para el control de la pandemia, ya que no confía en las medidas administrativas:

La higiene no dispone como en otras epidemias de medios eficaces para detener su propagación, y por consiguiente no se puede confiar en medidas administrativas para dominar la epidemia; y solamente pueden aconsejarse prescripciones individuales, no para detener la epidemia sino para disminuir su gravedad y prevenir las complicaciones ${ }^{50}$.

Recomienda en este comunicado la máxima autoridad sanitaria del país, el uso de la quinina; el aislamiento de ancianos, niños y enfermos respiratorios, por ser los más susceptibles; la desinfección de boca y nariz con soluciones de yodo; escupideras con formol; abrigar a los enfermos y darles infusiones calientes. También recalca que la Junta Central de Higiene «se permite insistir en la necesidad y urgencia de que la gobernación y el municipio establezcan asistencia médica para los enfermos pobres ${ }^{51}$. Dos días antes, la Alcaldía de Bogotá y la Gobernación de Cundinamarca, se comprometían a

49 Solano, Organización de la higiene Pública, 5.

50 El Nuevo Tiempo, Bogotá, 23 de octubre de 1918b, 1.

51 El Nuevo Tiempo, Bogotá, 23 de octubre de 1918b, 1. 
pagar las cuentas de los medicamentos de los pobres atacados por la gripa ${ }^{52}$.

El Gobernador de Cundinamarca, Restrepo Sáenz, promovió dos reuniones con la Junta Central de Higiene, los días 22 y 24 de octubre de 1918, con asistencia del Alcalde de Bogotá. En las que la Junta Central de Higiene acordó, el día 22 de octubre, las siguientes medidas para combatir la epidemia en la capital colombiana, entre las que se encuentra la creación de la Junta de Socorros:

1. Organizar la asistencia médica para atender en sus domicilios a los enfermos pobres. 2. Dividir la ciudad en ocho o diez zonas, cada una de las cuales debería ser atendida por un médico y un ayudante. 3. Establecer hospitalidad para los enfermos que en concepto de los médicos necesitaran los cuidados del hospital. 4. Crear una Junta de Socorros encargada de reunir recursos a fin de llevar a los enfermos pobres víveres, ropas, etc., y de organizar el servicio de los hospitales. 5. Autorizar al alcalde de la ciudad para nombrar el personal de la Junta de Socorros y para reglamentar las funciones de todos los médicos ${ }^{53}$.

El señor Santiago de Castro Maldonado, Alcalde de Bogotá, posesionado tan solo veinte días atrás ${ }^{54}$, mediante decreto 57 del día 23 de octubre de 1918, ordenó la creación de una Comisión Sanitaria encargada de «visitar todos los enfermos notoriamentepobresy expedirles las correspondientes fórmulas». Esta comisión fue conformada por los médicos: Miguel A. Rueda (Presidente de la Academia Nacional de Medicina 1918-1920), Pablo Llinás, Jorge Esguerra López, Enrique Fonseca, Jorge Bejarano ${ }^{55}$ y Jorge A. Camacho ${ }^{56}$.

52 El Nuevo Tiempo, Bogotá, 23 de octubre de 1918b, 1.

53 García Medina, «Informe del Director Nacional de Higiene al Ministro de Instrucción Pública,» 280-281.

54 Santiago de Castro Maldonado, fue nombrado Alcalde de Bogotá por el Gobernador de Cundinamarca Restrepo Sáenz, mediante decreto 207, del día 3 de octubre de 1918 (Mayorga García, 2011).

55 Jorge Bejarano (1888-1966) Médico de la Universidad Nacional especializado en París en pediatría e higiene. Fundador de la cátedra de higiene en la Universidad Nacional de Colombia en 1921. Presidente de la Cruz Roja Colombiana, de la Academia Nacional de Medicina y primer Ministro de Higiene de Colombia.

56 Gaceta Republicana, Bogotá, 25 de octubre de 1918b. 
En la reunión del 24 de octubre de 1918, se decidió dividir la ciudad de Bogotá en diez zonas para su atención, acordando que los gastos de médicos, practicantes y medicamentos, para ser distribuidos a los enfermos pobres, estarían a cargo del departamento y el municipio (Ver figura 2).
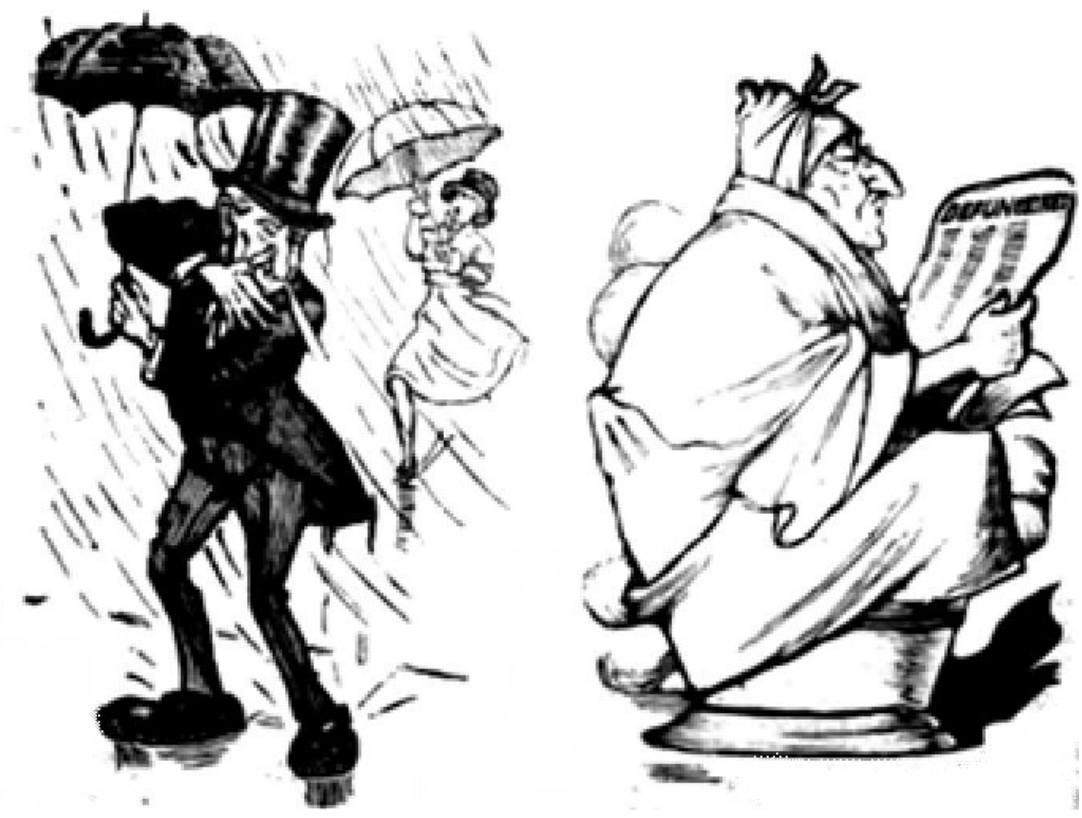

Figura 2. Caricatura del Gobernador de Cundinamarca y del Alcalde de Bogotá, titulada "Las Autoridades de la Ciudad», donde aparece el doctor Restrepo Sáenz, Gobernador de Cundinamarca, «el más "sonado" de todos los Gobernadores, por su actividad desmedida para combatir la grippe». Y el señor Alcalde de la ciudad «experimentando en cabeza propia el último procedimiento inventado por el doctor Solano para combatir la grippe»

Fuente: «Las Autoridades de la Ciudad», Bogotá Cómico, Bogotá, octubre de 1918b, 1 .

Según el informe oficial del doctor Pablo García Medina, al terminar la reunión en la que se resolvió la creación de la Junta de Socorros, se presentaron los señores: Enrique Liévano, Manuel Dávila Flórez y Julio D. Portocarrero, quienes ofrecieron sus servicios, preocupados ante la grave situación ocasionada por la epidemia de gripa. El gobernador solicitó a estos señores que aceptaran hacer parte de la Junta de Socorros, agregando a estos, a Eduardo Carvajal y al general 
Enrique Palacios ${ }^{57}$; sin embargo, la versión de Eduardo Carvajal, encargado del informe de la Junta de Socorros al final de la pandemia, en su exposición publicada en noviembre de 1918, contradice totalmente, como lo hace la prensa local, la versión oficial promulgada por la Dirección Nacional de Higiene, a cargo del doctor Pablo García Medina, posesionado al finalizar la pandemia en Bogotá, en enero de 1919.

El 24 de octubre de 1918, Eduardo Carvajal, su esposa y el banquero Ernesto Michelsen ${ }^{58}$, caminando por las calles del centro de Bogotá, se encuentran frente a la siguiente situación, según lo cuenta el mismo Carvajal en su informe:

[...] encontraron una pobre mujer del pueblo apenas cubierta con algunas desgarrados harapos, con la cabeza apoyada sobre una piedra, tendida sobre charcos de agua. Estaba agonizando. Los caballeros y la dama nombrados trataron de presentarle algún auxilio: un médico, una bebida caliente, un carruaje que la llevara al hospital. Este establecimiento no podía recibir ya más enfermos. Fue imposible conseguir para la agonizante refugio alguno, y allí murió -en el centro de una ciudad civilizada- en el más trágico y amargo de los abandonos ${ }^{59}$.

Después de esto, los señores Carvajal y Michelsen se dirigieron inmediatamente a la Gobernación y a la Alcaldía. El Alcalde, respaldado y presionado por la élite capitalina, crea la Junta de Socorros mediante decreto 59 de 1918, expedido el día 24 de octubre, para atender a los atacados de la epidemia reinante que no tengan recursos con qué atender su curación y para asilar a los pobres atacados por la epidemia reinante. Son integrantes de la Junta el Doctor

57 García Medina, «Informe del Director Nacional de Higiene al Ministro de Instrucción Pública,».

58 Ernesto Michelsen Mantilla, era el Gerente del Banco de Colombia en el momento de la epidemia, Ernesto Michelsen dirigió durante varios años el Banco Central Hipotecario y es el padre del, también, banquero Jaime Michelsen Uribe.

59 Carvajal, Exposición de la Junta de Socorros. Bogotá. Arboleda y Valencia, 1011. 
Manuel Dávila Flórez ${ }^{60}$. General Enrique Palacios M. ${ }^{61}$, Julio D. Portocarrero ${ }^{62}$, Enrique Liévano, Ernesto Michelsen, Pedro López P. ${ }^{63}$ y Eduardo Carvajal ${ }^{64}$. Aclara este decreto que la Junta de Socorros sería auxiliar de la Comisión Sanitaria que habían creado el día anterior ${ }^{65}$. La Junta de Socorros eligió sus dignatarios: Presidente, Manuel Dávila Flórez; Tesorero Pedro López Pumarejo y Secretario, Guillermo Pérez Sarmiento.

Lo dicho por la Junta de Socorros es ratificado por la prensa, como es el caso de una noticia que aparece en El Diario Nacional en noviembre 6 de 1918:

[...] para conocimiento del público queremos dejar constancia de que la Junta de Socorros, esa altruista junta a la que Bogotá tanto le debe, no fue fundada por la Junta Central de Higiene, como se ha dicho, la Junta de Socorros es obra de unos caballeros bien conocidos en la ciudad, por su espíritu de progreso, el señor Gobernador, y el Alcalde. A Dios lo que es de $\operatorname{Dios}^{66}$.

En la Revista Cromos de noviembre 2 de 1918, se publica la historia de la pobre mujer agonizante a la que socorren los señores Michelsen y Carvajal, resaltando el origen privado

60 Manuel Dávila Flórez (1853-1924). Político conservador momposino, abogado y pedagogo, rector de la Universidad de Cartagena, Ministro de Instrucción Pública en 1910 y senador de la República en el periodo 1912-1915.

61 El general Enrique Palacios Medina se reporta como afectado por la pandemia de gripa en Bogotá. Fue también fundador en 1912 de la Academia Vallecaucana de la Historia.

62 Julio D. Portocarrero se desempeñaba como Secretario del Senado en 1918 y continúa siéndolo en 1928.

63 Pedro López Pumarejo. Hijo del banquero Pedro A. López, quien organizó la Casa Comercial López y el Banco López y se involucró en política a nombre del Partido Liberal; Pedro A. López fue concejal de Bogotá entre 1917 y 1919, es decir, durante la pandemia de gripa, además de ser ministro del Tesoro. Pedro López Pumarejo es hermano del dos veces presidente de Colombia en los años 30', Alfonso López Pumarejo.

64 Eduardo Carvajal y Dávila Flórez, aparecen como médicos en varios estudios publicados sobre la pandemia de Gripa de 1918. Pero Dávila Flórez es abogado y pedagogo y como se puede ver en el periódico el Tiempo, en un aviso, Eduardo Carvajal se desempeña como abogado y comisionista (El Tiempo, 1917).

65 El Nuevo Tiempo, Bogotá, 3 de noviembre de 1918d.

66 El Diario Nacional, Bogotá, 6 de noviembre de 1918d, 1. 
de la Junta de Socorros hasta ahora, según la revista, desconocido ${ }^{67}$.

A la primera reunión de la Junta de Socorros, realizada el 24 de octubre, asistieron sus miembros y personalidades de la élite capitalina como: Nemesio Camacho ${ }^{68}$, Luis Suárez Castillo, Eduardo Santos ${ }^{69}$ y Santiago Grajales ${ }^{70}$. También concurrieron los médicos que conformaban la Junta Sanitaria, Miguel A. Rueda, Pablo Llinás, Jorge Esguerra López, Enrique Fonseca, Jorge Bejarano y Jorge A. Camacho, en asocio del señor Alcalde de la ciudad ${ }^{71}$. En esta reunión el Gobernador de Cundinamarca, pone en conocimiento a los miembros de la Junta Central de Higiene, de la presencia de la epidemia en algunos municipios del departamento tomando la Junta las siguientes medidas: 1. Nombrar comisiones sanitarias, conformadas por un médico y un ayudante en los municipios afectados por la gripa. 2. El suministro de medicinas a las diferentes comisiones para atender a los enfermos. 3. Destinar $\$ 3000$ del Tesoro Nacional para ayudar a los gastos que ocasionará la lucha contra la epidemia en el departamento; este punto se sometió a la aprobación del Poder Ejecutivo, de acuerdo con la Ley 84 de 1914. Las comisiones sanitarias mencionadas fueron conformadas por 83 estudiantes de quinto y sexto año, de la Facultad de Medicina de la Universidad Nacional de Colombia y por médicos que, en su mayoría, trabajaron de manera gratuita ${ }^{72}$.

Pablo García Medina, tratando de reivindicar el papel del organismo rector de la higiene en Colombia, afirma:

67 Cromos, Bogotá, 2 de noviembre de 1918c.

68 Nemesio Camacho Macías (1869-1929) abogado, político, banquero y empresario. Fue Ministro de Obras Públicas; Miembro de la Asamblea Nacional Constituyente, Senador y Representante a la Cámara por el Partido Liberal y gerente del Banco Central, del Tranvía de Bogotá y del Ferrocarril del Pacífico.

69 Eduardo Santos (1888-1974), director del periódico El Tiempo en el momento de la Pandemia, fue abogado, político y periodista, miembro del Partido Liberal y presidente de la República de 1938 a 1942.

70 El Diario Nacional, Bogotá, 25 de octubre de 1918b.

71 Gaceta Republicana, Bogotá, 19 de octubre de 1918a.

72 El Nuevo Tiempo, Bogotá, 3 de noviembre de 1918d. 
[...] la Junta Central de Higiene, además dirigió circulares por telégrafo a los gobernadores y a los directores departamentales para darles cuenta de la marcha de la epidemia, comunicarles las medidas que se habían tomado para que procedieran de acuerdo y para delegarles la facultad de nombrar las comisiones sanitarias municipales de que trata la Ley ${ }^{73}$.

El 25 de octubre se suspende el servicio nocturno del tranvía en Bogotá, y, además, se destinaron los carros del municipio para trasladar los cadáveres de los indigentes, provenientes de los diferentes barrios de la ciudad, al anfiteatro. Otros vehículos del municipio fueron adecuados para poder trasladar enfermos a los hospitales provisionales instaurados por la Junta de Socorros en la ciudad. La Junta de Socorros abre el primer hospital en La Hortúa, para aislar a los pobres de la ciudad afectados por la pandemia de Gripa.

Informa el diario Sur América, que el Senado de la República no funciona a causa de la epidemia y que en la Cámara de Representantes el día 25 de octubre "Pasa el primer debate sobre el proyecto que vota un auxilio de $\$ 40.000$ para defender la nación de la epidemia de la gripa». Proyecto que la Cámara aprobó el día siguiente: con los votos de todos los representantes, excepto el de Sotero Peñuela, ingeniero y representante conservador del Departamento de Boyacá, quien afirmaba que tal proyecto solo favorecería al departamento de Cundinamarca y a la ciudad de Bogotá y que, por consiguiente, la República no debía hacer el gasto de los $\$ 40.000$ que votaba el proyecto, que según él, «le corresponde hacerlo a aquellas entidades» ${ }^{74}$ (Ver figura 3). El proyecto lo aprobó, en segundo debate el Senado hasta el 1 de noviembre, cuando la curva pandémica estaba ya en pleno descenso; sin embargo, El Diario Nacional el 18 de noviembre publica una comunicación que le hace el presidente de la Junta de Socorros, Manuel Dávila Flórez, al ministro de Gobierno en donde le pide dar un informe sobre el auxilio aprobado, es decir, sobre los: $« \$ 40000$ pesos votados por ley reciente, con destino a las

73 García Medina, «Informe del Director Nacional de Higiene al Ministro de Instrucción Pública,».

74 Sur América, Bogotá, 29 de octubre de 1918b, 1. 
víctimas de la epidemia ¿el gobierno piensa dar alguna parte de aquella?» ${ }^{75}$.

En el informe final de la Junta de Socorros, que elabora Eduardo Carvajal, concluye que:

En la considerable suma que la caridad de Bogotá y de algunas otras ciudades puso en manos de la Junta, no figura un centavo de procedencia oficial atribuible al Municipio, al Departamento, o la Nación (...) si seguimos esperando todo de la acción oficial estaremos condenados al estancamiento ${ }^{76}$.

El 17 de noviembre, delegaciones de los gremios y sociedades obreras realizaron una manifestación pública en agradecimiento a los miembros de la Junta de Socorros, después de elogiar la labor de los miembros de la Junta, se quejan de una mancha negra que, para ellos, aparecía en medio de tanto resplandor:

[...] me refiero, señor, a una dádiva que se hizo entre los miembros del Congreso para beneficiar a los enfermos pobres, esa dádiva que asciende a dos pesos fue hecha por el señor Sotero Peñuela, representante por el departamento de Boyacá. Como ese ciudadano viene trabajando constantemente, con enérgico tesón, con tenacidad digna de mejor causa, contra todo proyecto de ley que entrañe si quiera sea el más leve beneficio para Bogotá y los obreros, los obreros de la capital nos vemos obligados, por dignidad del gremio, por orgullo natural en el hombre a rechazar esa dádiva; y la rechazamos señor; por tanto pedimos que ella sea devuelta, porque no estamos dispuestos a agradecerla ${ }^{77}$.

El día 29 de octubre, Marco Fidel Suárez, Presidente de la República y el secretario del Ministerio de Instrucción Pública, mediante decreto suspendieron tardíamente los exámenes anuales y daban por terminado el año escolar de los establecimientos de educación de Bogotá, muchos de ellos con internados. Los estudiantes de provincia seguramente retornaron a sus regiones de origen, diseminando el virus de

75 Sur América, Bogotá, 2 de noviembre de 1918d, 1.

76 Carvajal, Exposición de la Junta de Socorros. Bogotá. Arboleda y Valencia, 96.

77 Carvajal, Exposición de la Junta de Socorros. Bogotá. Arboleda y Valencia, 8586. 
la gripa por el país. El 30 de octubre aparece una nota en la Gaceta Republicana suspendiendo todavía los espectáculos públicos por el miedo al contagio. El mismo día, el Alcalde de la ciudad expidió un decreto para "ampliar el cementerio en su parte sur» y construir nuevas bóvedas, ya que este estaba saturado por las víctimas de la letal pandemia ${ }^{78}$.

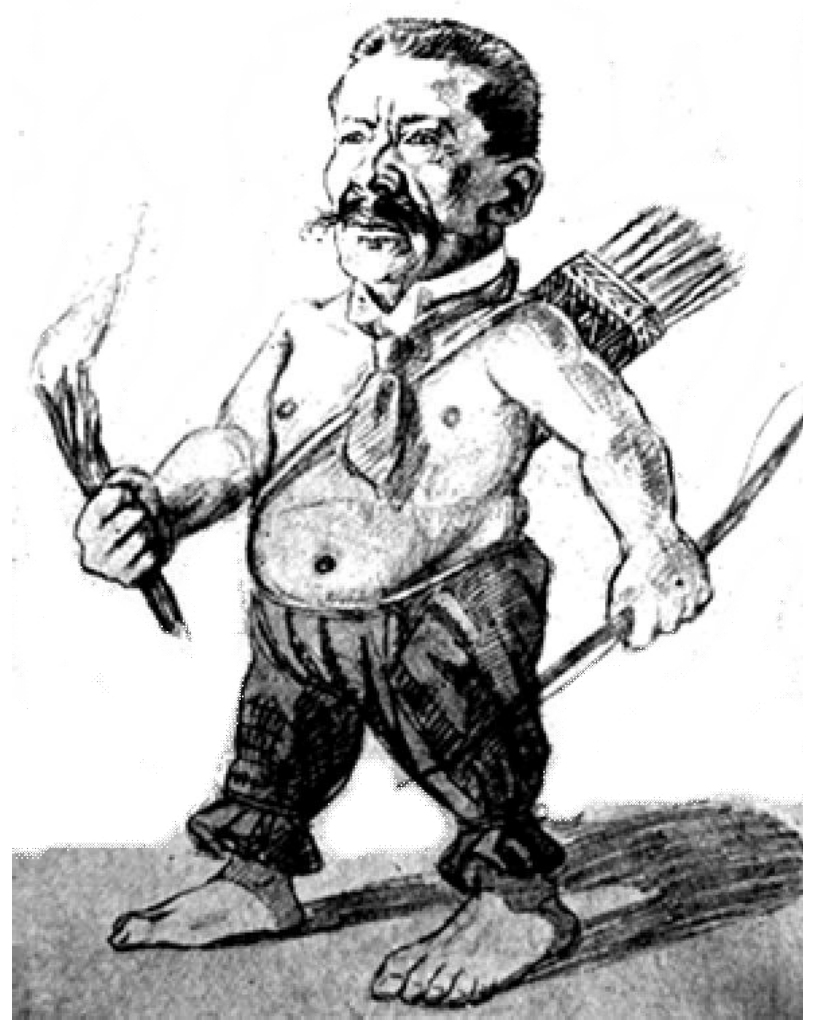

Figura 3. Caricatura de Lápiz, del Representante conservador boyacense Sotero Peñuela, «cuya agresiva y áspera actuación en los debates parlamentarios culminó el jueves último fomentando en la Cámara un grave escándalo, contra el cual protestaron unánimemente los miembros de esa Corporación y los Senadores allí presentes».

Fuente: «El Representante Sotero Peñuela», Bogotá Cómico, Bogotá, octubre de $1918 \mathrm{c}, 2$.

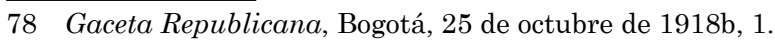


El 30 octubre la Oficina Municipal de Higiene ordenaba la desinfección diaria de los carros del tranvía, la desinfección de casas, hoteles y establecimientos de educación donde han ocurrido defunciones diagnosticadas de origen gripal. Las licencias para conducir en carruaje al cementerio los cadáveres de los párvulos fueron suspendidas. El Alcalde prohibió los entierros de cuerpo presente en todas las iglesias de la ciudad; los cadáveres debían ser conducidos directamente al cementerio; también se suspendió el procedimiento de levantamiento de cadáveres, el acompañamiento de los familiares al cementerio, las celebraciones del día de los difuntos y se pidió al arzobispo de Bogotá la suspensión del redoble de las campanas "teniendo en cuenta el estado nervioso de los bogotanos», sobre todo el de los afectados por la pandemia ${ }^{79}$.

El 31 de octubre, la Junta de Socorros se reorganiza en cuatro secciones de la siguiente manera: Sección de víveres dirigida por Alejandro Tamayo ${ }^{80}$, encargada de recoger las donaciones de alimentos, así como de comprarlos con el dinero de la Junta, para repartirlos entre los hospitales y los habitantes de los barrios pobres. Sección Abrigos a cargo de Julio Holguín; Sección de los Hospitales a cargo de Eduardo Carvajal y Sección de medicinas y caja, bajo la dirección de Pedro N. López.

El 5 de noviembre la Junta de Socorros es comisionada para exponer ante el honorable Consejo de Ministros y el Presidente de la República algunas ideas de cómo prevenir futuras epidemias ${ }^{81}$. El 6 de noviembre el Vicepresidente de la Junta de Socorros, Enrique Liévano, hablaba ante el Consejo de Ministros y manifestaba las acciones realizadas por la Junta de Socorros que, hasta el momento, mediante la solidaridad y la caridad pública había contribuido con una suma «que no baja de treinta y cinco mil pesos oro, se ha podido asilar en diversos hospitales más de mil enfermos, se da alimentación a

79 El Diario Nacional, Bogotá, 31 de octubre de 1918c, 1.

80 Alto funcionario de la Compañía Colombiana de Seguros.

81 El Diario Nacional, Bogotá, 6 de noviembre de 1918d. 
siete mil personas en todos los barrios, a los infelices que las solicitan». Estas acciones, ratificaba Liévano, empezaron de forma tardía «cuando había más del 70 por 100 de la población atacada de la enfermedad $»^{82}$.

El Ministerio de Gobierno dirigió una circular a toda la República, tendiente a calmar la alarma y a encarecer las medidas preventivas para evitar el contagio de la gripa. Se prohibió la entrada de personas sanas al cementerio y se inauguró uno nuevo al norte de la ciudad, en Chapinero. Se ordenó a los presos abrir las fosas comunes al agotarse rápidamente las tumbas disponibles en el cementerio central:

Algunas familias han enterrado sus deudos en el cementerio laico o de los suicidas, además se han hecho grandes fosas comunes que cada rato se llenan con los cuerpos de los desvalidos (...) Se han puesto al servicio numerosos carros de ambulancia para trasladar enfermos a los hospitales y otros para llevar los cadáveres al cementerio ${ }^{83}$.

El informe final que presenta la Junta de Socorros hace una mención especial a «el admirable servicio de ambulancia médica que organizaron la Gobernación y la Alcaldía» ${ }^{84}$ (ver figura 7). El 2 de noviembre, el Concejo de Bogotá expidió un acuerdo mediante el cual se destinaban $\$ 6000$ pesos, provenientes de la renta de los cementerios para combatir la epidemia que azotaba la ciudad y para poder dar atención a los pobres que necesitaran de la protección oficial ${ }^{85}$.

La solidaridad de las industrias y empresas capitalinas es frecuentemente resaltada en la prensa local:

El señor Carlos A. Dávila ${ }^{86}$ con generosidad que nos merece efusivo elogio, ha tomado a su cargo y por su cuenta el Hospital de Chapinero hasta en sus más mínimos gastos y necesidades.

82 El Diario Nacional, Bogotá, 6 de noviembre de 1918d, 3.

83 Sur América, Bogotá, 31 de octubre 1918c, 1.

84 Carvajal, Exposición de la Junta de Socorros. Bogotá. Arboleda y Valencia, 16.

85 Acuerdo 40/1918, 2 de noviembre, Consejo de Bogotá.

86 Carlos A. Dávila es el Gerente del Ferrocarril del Norte, quien donó dinero para la fundación y organización del Hospital de Varones de Chapinero, creado durante la pandemia, en el Edificio de la Escuela Superior de Guerra. 
Las fábricas de Bavaria y Fenicia abrieron hospitales para sus obreros enfermos, les han pagado íntegro su salario, aun cuando por el flagelo no presten sus servicios, han costeado el entierro de quienes han fallecido, y han abierto cocinas gratuitas para darles alimentos reconfortantes. Otro tanto han hecho los señores Samper Brush en sus empresas de energía y fábrica de cemento. Los gerentes de los ferrocarriles dictaron varias medidas que facilitan los auxilios a la ciudad y que favorecen a sus obreros. Todas estas cosas merecen el eterno reconocimiento de los bogotanos y los más francos aplausos $^{87}$.

La prensa, de igual manera, resalta el importante papel desempeñado por las damas de la élite bogotana en la atención de las víctimas de la pandemia de gripa:

Comisiones de honorabilísimas señoras se encargaron de visitar las insalubres y asquerosas viviendas de tantos desdichados, y de recoger bajo la lluvia y entre el lodo de los muladares, los cadáveres ${ }^{88}$.

El informe final de la Junta de Socorros reconoce la ayuda de las colonias y embajadas de Inglaterra, Francia, Bélgica y Siria que fundaron trece comedores, y cuatro restaurantes populares en los cuales se repartían alimentos para las clases menesterosas, atendiendo a cinco mil personas durante la pandemia. El embajador de Italia obsequió 400 vestidos a los niños y la embajada de los Estados Unidos donó y recolectó dinero entre sus conciudadanos ${ }^{89}$.

87 Sur América, Bogotá, 2 de noviembre de 1918d, 1.

88 Sur América, Bogotá, 9 de Noviembre de 1918e, 1.

89 Carvajal, Exposición de la Junta de Socorros. Bogotá. Arboleda y Valencia. 


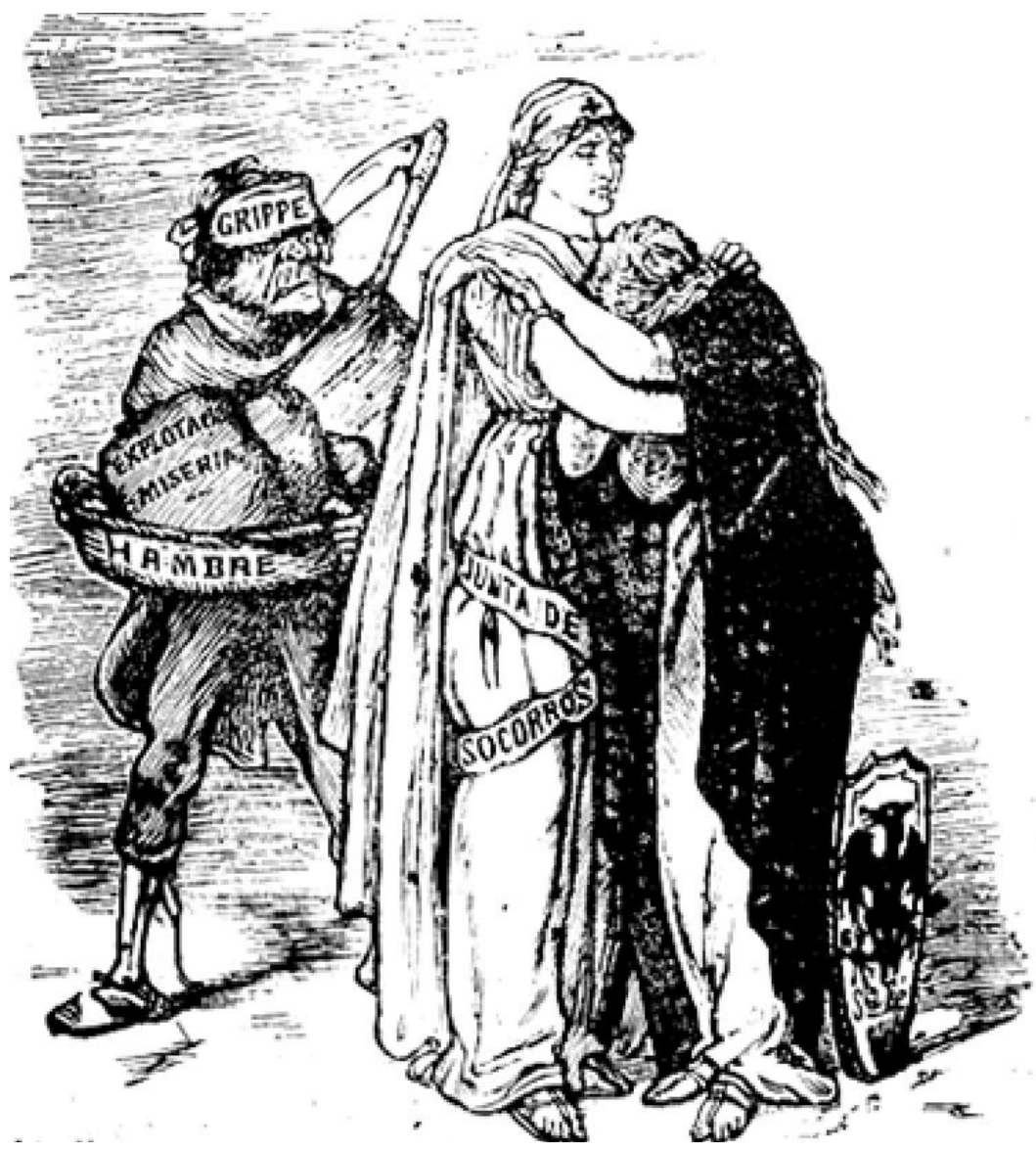

Figura 4. Bogotá y la Junta de Socorros. La Junta de Socorros protegiendo y consolando a la capital colombiana, devastada por la gripa, el hambre, la explotación y la miseria, le dice: «No llores, noble ciudad, que por cada Sotero hay mil corazones generosos que os quieren y os defenderán de la peste y el hambre». Xilografía de Pepe Gómez

Fuente: «Las víctimas de la gripa», Bogotá Cómico, Bogotá, 2 de noviembre de 1918d.

A nivel nacional, sobresalen las contribuciones realizadas en las ciudades de Barranquilla, Cali y Cúcuta, que enviaron importantes sumas de dinero con destino a la Junta de Socorros de Bogotá, así como lo hizo la comunidad taurina, que realizó varias corridas de toros para recolectar recursos con destino a los afectados por la pandemia. También colaboraron empresas de servicios públicos como las compañías 
de teléfonos, del acueducto y electricidad, que dotaron de sus servicios y no cobraron la cuenta a los hospitales provisionales creados por la Junta de Socorros; diarios como El Siglo, que colocaron a disposición de la Junta la imprenta para sus comunicados; la empresa de ferrocarriles, que contribuyó con el traslado gratuito de los enfermos y el Ejército Nacional, que colaboró con la adecuación de 100 camas para ser ubicadas en los hospitales provisionales ${ }^{90}$.

En una crónica sobre lo sucedido con la pandemia de gripa en el Paseo Bolívar, se insiste en la necesidad de mejorar las condiciones higiénicas de esta zona de pobreza con los mayores niveles de mortalidad e insalubridad de la capital colombiana:

[...] cuanta reprobación acerba no merecen las autoridades municipales que jamás dirigieron hacia allí la necesaria vigilancia, que nunca se han preocupado por poner en vigor las reglas de la higiene entre las clases infelices y que han permitido que nazcan y se desarrollen todos aquellos males en un lugar que por su situación y su natural belleza debiera ser un verdadero paseo, digno de la capital de la república y del famoso nombre del Libertador (...) Al Concejo, al Alcalde, a la junta de Higiene, a la sociedad de Embellecimiento y en general a los habitantes de Bogotá, corresponde hacer este esfuerzo. Al Congreso le toca determinar la manera de construir las humildes moradas en que hayan de cobijarse los infortunados habitantes del Paseo Bolívar, ya que allí es imposible que sigan viviendo ${ }^{91}$.

El 20 de noviembre de 1918, se publica en el Diario Nacional, una carta del doctor Cenón Solano con fecha del 9 de noviembre, dirigida al dirigente político conservador Laureano Gómez, denunciando que sus advertencias no habían sido oídas y citando a Eduardo González Camargo, Subdirector de Higiene Municipal de Bogotá, hasta diciembre de 1917, quien había demostrado que en el Paseo Bolívar concurre el 95 por 100 de la mortalidad de Bogotá, pero esa mortalidad pertenece a la plebe, a las clases desvalidas, a los

90 María Fernanda Durán Sánchez, La gripe española en Bogotá: la epidemia de 1918 (Bogotá: Alcaldía Mayor de Bogotá, 2006).

91 Sur América, Bogotá, 9 de Noviembre de 1918e, 1. 
parroquianos de las chicherías, elenco de la miseria y el delito; por eso nadie conmueve a ninguna autoridad preocupada ${ }^{92}$.

\section{| Las victimas de la gripa |}

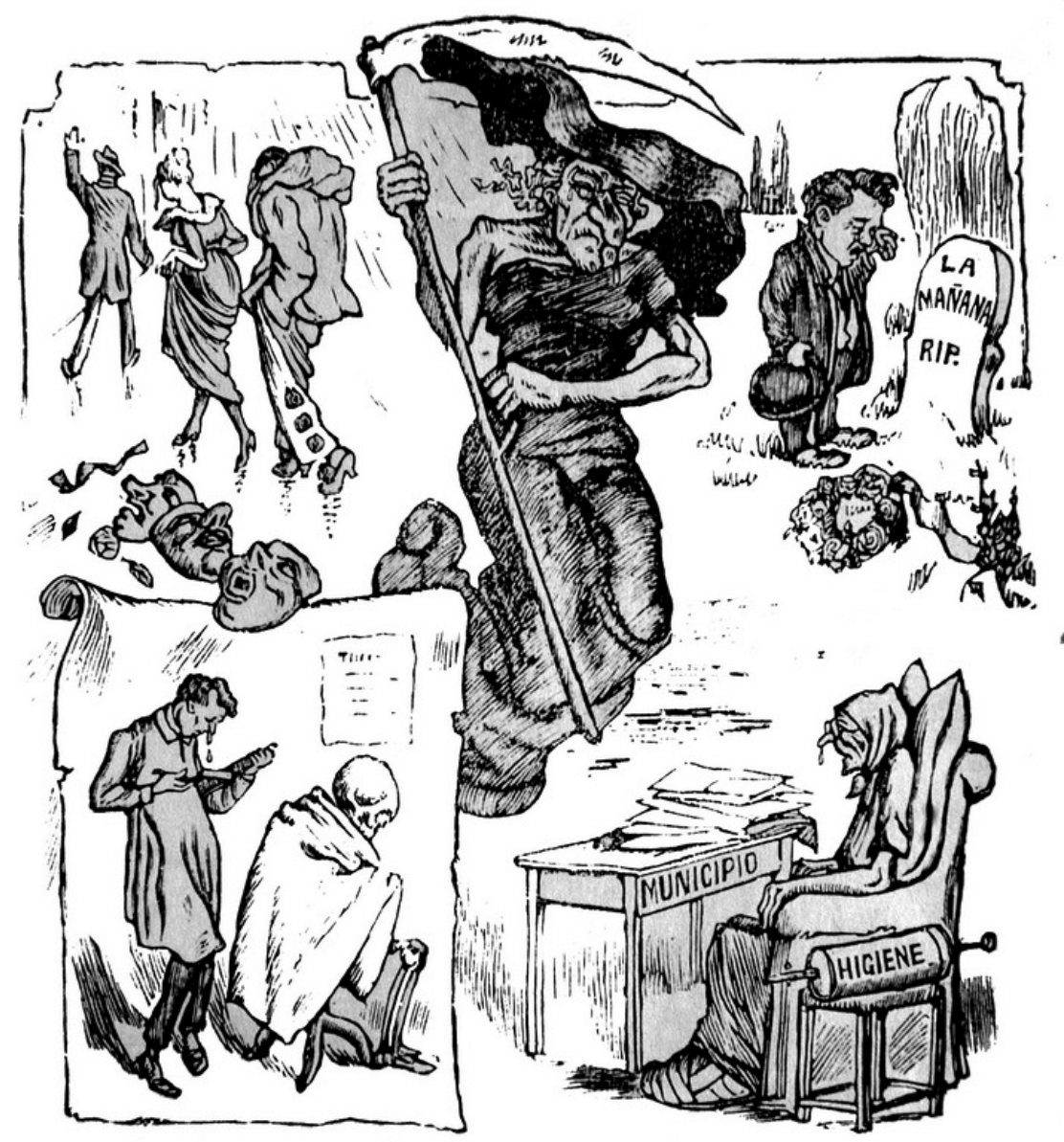

Figura 5. "Y la Junta de Higiene, por chiripa, También ha muerto a manos de la gripa». Entre los damnificados por la epidemia se contaban los peluqueros, la prensa local, los cómicos y la Higiene Municipal, como lo evidencian las caricaturas aparecidas en la revista Bogotá Cómico de octubre y noviembre de 1918

Fuente: «Las víctimas de la gripa,» 1

92 El Diario Nacional, Bogotá, 20 de noviembre de 1918e, 3. 
A los pocos días de finalizar en Bogotá la epidemia de gripa, el Estado colombiano promulgó la Ley 46, del 19 de noviembre de 1918, "por la cual se dicta una medida de salubridad pública y se provee a la existencia de habitaciones higiénicas para la clase proletaria ${ }^{93}$, iniciándose en Colombia la intervención estatal para la creación de vivienda obrera en Bogotá, con el fin de dar solución a la insalubridad del Paseo Bolívar, que como se ha registrado, era el sitio de mayor mortalidad de Bogotá, adjudicando el 2\% de los impuestos municipales a la construcción de vivienda obrera, permitiendo así crear instituciones que se dedicaran a la construcción de la vivienda higiénica, además de aplicar ideas urbanísticas modernas y crear los primeros barrios obreros de la ciudad ${ }^{94}$.

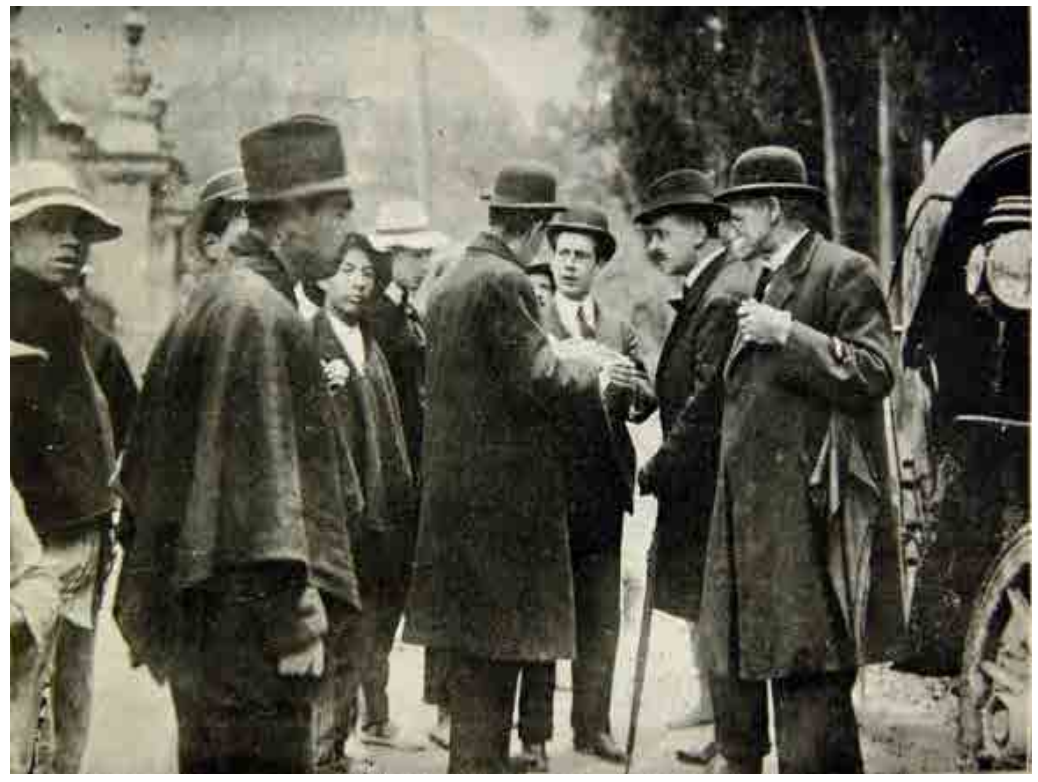

Figura 6. En la fotografía publicada en la revista Cromos, aparecen algunos miembros de la Junta de Socorros, frente al hospital provisional que estaba ubicado en el antiguo claustro de San Diego

Fuente: «La ambulancia prestando un socorro en la vía pública. Bogotá», Cromos, Bogotá, 2 de noviembre de 1918d, 263.

$\overline{93}$ Ley 46/1918, 19 de noviembre, por la cual se dicta una medida de salubridad pública y se provee a la existencia de habitaciones higiénicas para la clase proletaria, 1.

94 Yenny Milena Cotrino Díaz, «La vivienda obrera un elemento modernizador: la intervención del Estado en Bogotá, 1918-1942,» Revista de Arquitectura, 9, (2007): $5-12$. 


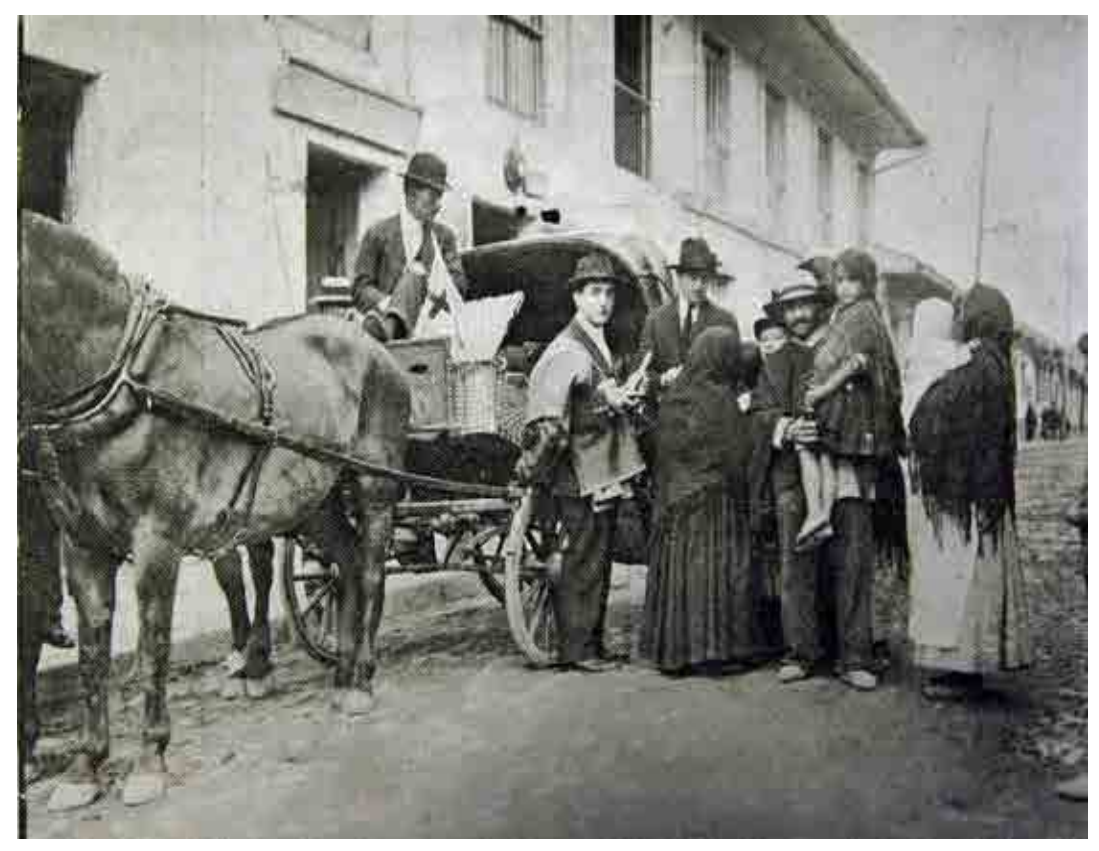

Figura 7. En esta fotografía de la revista Cromos, aparece la ambulancia de tracción animal «prestando un socorro en la vía pública», en Bogotá, durante la pandemia de gripa

Fuente: «La ambulancia prestando un socorro en la vía pública. Bogotá», 262.

\section{Conclusiones}

La institución que desempeñó el papel más importante en la atención a la población marginada fue la Junta de Socorros, creada por iniciativa privada. Estaba conformada por banqueros, comerciantes de la ciudad y damas de la alta sociedad, organizados para tal fin. La Junta de Socorros creó en Bogotá 6 hospitales provisionales, 13 comedores, salones de costura donde se confeccionaron 2395 prendas de vestir. La Junta realizó 270 visitas domiciliarias para aprovisionar de ropas y alimentos a las familias con enfermos y 700 visitas a familias para prestar atención médica, como resultado de ellas se hospitalizaron 350 enfermos. Resulta llamativo que ningún médico capitalino formara parte de la organización directiva de la Junta de Socorros ${ }^{95}$.

95 Carvajal, Exposición de la Junta de Socorros. Bogotá. Arboleda y Valencia. 
La Higiene Pública, en manos del Estado, se mostró incapaz de hacer frente a la pandemia, siendo la Junta de Socorros, un organismo privado constituido por los notables de la capital, la única institución que realizó acciones efectivas con los afectados. Esta institución aparece recordada y alabada por los medios escritos, en contraposición a la Dirección Nacional y Municipal de Higiene, que fueron fuertemente criticadas por su escasa intervención ante la pandemia y representadas como víctimas en las caricaturas.

En medio de las reformas sanitarias del país, la Higiene Pública se reestructura en plena pandemia de gripa en octubre de 1918. La Junta Central de Higiene como organismo asesor, además de enfermarse de gripa médicos y empleados administrativos, no pasó de dar consejos de higiene privada, sosteniendo que las medidas administrativas eran inútiles. Se destaca el papel desempeñado por el Gobernador del Departamento de Cundinamarca y por el Alcalde de Bogotá, que, a pesar de no aportar recursos económicos, movilizaron a la administración pública para actuar frente a la pandemia, bajo la coordinación de la Junta de Socorros.

El único aporte económico por parte del Estado tanto a nivel nacional, departamental y municipal parece haber sido los 2 pesos donados por el criticado representante conservador boyacense Sotero Peñuela, al tiempo de oponerse a la partida destinada por el Congreso de la República al momento de la pandemia, que los sindicatos bogotanos piden públicamente, que les sean devueltos al congresista.

Tras los devastadores efectos causados por la pandemia de gripa de 1918, se inicia en Colombia la intervención estatal para la construcción de viviendas obreras higiénicas, que termina en la creación de los primeros barrios obreros de Bogotá.

\section{Bibliografía}

Archila, Mauricio. Cultura e identidad obrera. Colombia 1910-1945. Bogotá: CINEP, 1991. 
Carvajal, Eduardo. Exposición de la junta de socorros. Bogotá. Arboleda y Valencia. Tunja: Museo de historia de la medicina y la salud. Universidad Pedagógica y Tecnológica de Colombia, 1918.

Castilla, Enrique. Historia de la gripa en Colombia. Tesis Doctoral. Bogotá: Tipografía ideal, 1922.

Cotrino Díaz, Yenny Milena. «La vivienda obrera un elemento modernizador: la intervención del estado en Bogotá, 19181942.» Revista de Arquitectura, 9, (2007): 5-12.

Durán Sánchez, María Fernanda. La gripe española en Bogotá: la epidemia de 1918. Bogotá: alcaldía mayor de Bogotá, 2006.

Flórez, Carmen Elisa. Las transformaciones socio-demográficas en Colombia durante el siglo XX. Bogotá: Banco de la República y Tercer Mundo Editores, 2000.

García Medina, Pablo. «Informe del Director Nacional de Higiene al Ministro de Instrucción Pública.» Revista de Higiene, 9 (115) (1919): 279-310.

García Medina, Pablo. "La organización sanitaria en colombia.» Boletín de la Oficina Sanitaria Panamericana, 6 (2) (1927): 3-14.

Hernández Álvarez, Mario. La salud fragmentada en Colombia, 1910-1946. Bogotá: Instituto de Salud Pública, Universidad Nacional de Colombia, 2002.

Laverde, Jorge. Contribución al estudio de la epidemia de gripe, en Bogotá, en 1918. Tesis doctoral. Bogotá: tipografía artística, 1918.

Londoño, Patricia, y Santiago Londoño. "Vida diaria en las ciudades colombianas.» En Nueva Historia de Colombia, dirigido por Álvaro Tirado, 318- 337. Bogotá: planeta colombiana, 1989.

Mayorga García, Fernando. «Bogotá, bajo la república unitaria: 1886-2010.» En Historia Institucional de la Alcaldía De Bogotá, dirigido por Fernando Mayorga García, 1-244. Bogotá, Alcaldía de Bogotá: Universidad del Rosario, 2011. 
Mejía Pavony, Germán. «Los itinerarios de la transformación urbana. Bogotá, 1820-1910.» Anuario Colombiano de Historia Social y de la Cultura, 24, (1997): 101-137.

Melo, Jorge Orlando. «La idea del progreso en el siglo XIX, ilusiones y desencantos, 1780-1930.» XVI Congreso de colombianistas, Charlottesville, 6 de agosto de 2008.

Miranda Hernández, Álvaro. «Treinta días persiguiendo la muerte: miseria, dolor y obras de caridad en Bogotá de 1918, desolada por la epidemia de gripa.» Boletín Cultural y Bibliográfico, 45 (78) (2008): 40-61.

Noguera, Carlos Ernesto. Medicina y Política: discurso médico y prácticas higiénicas durante la primera mitad del siglo XX en Colombia. Medellín: Universidad Eafit, 2003.

Palacios, Marco. Entre la legitimidad y la violencia. Colombia 18751994. Bogotá: Editorial Norma, 2003.

Quevedo Vélez, Emilio, Catalina Borda, Juan Carlos Eslava, Claudia Mónica García, María Del Pilar Guzmán, Paula Mejía, y Carlos Ernesto Noguera. Café y gusanos, mosquitos y petróleo: el tránsito desde la higiene hacia la medicina tropical y la salud pública en Colombia, 1873-1953. Bogotá: Universidad Nacional de Colombia, 2004.

Solano, Cenón. Organización de la higiene Pública. Bogotá: Imprenta de El Siglo, 1918.

Vega Cantor, Renán. Gente muy rebelde. Enclaves, transportes y protestas obreras. Bogotá: Pensamiento Crítico, 2000.

\section{Fuentes primarias}

\section{Prensa}

«El abrazo de Suárez». Bogotá Cómico, Bogotá, octubre de 1918a.

«Las Autoridades de la Ciudad». Bogotá Cómico, Bogotá, octubre de 1918b. 
«El Representante Sotero Peñuela». Bogotá Cómico, Bogotá, octubre de 1918c.

«Las víctimas de la gripa». Bogotá Cómico, Bogotá, 2 de noviembre de 1918d.

«La Gripa. Habla el Presidente de la Junta Central de Higiene». El Nuevo Tiempo, Bogotá, 22 de octubre de 1918a.

«La ambulancia prestando un socorro en la vía pública. Bogotá». Cromos, Bogotá, 2 de noviembre de 1918d.

Cromos, Bogotá, 16 de octubre de 1918a.

Cromos, Bogotá, 26 de octubre de 1918b.

El Diario Nacional, Bogotá, 17 de octubre de 1918a.

El Diario Nacional, Bogotá, 25 de octubre de 1918b.

El Diario Nacional, Bogotá, 31 de octubre de 1918c.

El Diario Nacional, Bogotá, 6 de noviembre de 1918d.

El Diario Nacional, Bogotá, 20 de noviembre de 1918e.

El Gráfico, Bogotá, 19 de octubre de 1918b.

El Nuevo Tiempo, Bogotá, 23 de octubre de 1918b.

El Nuevo Tiempo, Bogotá, 31 de octubre de 1918c.

El Nuevo Tiempo, Bogotá, 3 de noviembre de 1918d.

El Tiempo, Bogotá, 09 de junio de 1918 (1917a).

El Tiempo, Bogotá, octubre de 1918b.

El Tiempo, Bogotá, 01 de octubre de 1918c.

El Tiempo, Bogotá, 22 de noviembre de 1918d. 
Gaceta Republicana, Bogotá, 19 de octubre de 1918a.

Gaceta Republicana, Bogotá, 25 de octubre de 1918b.

Gaceta Republicana, Bogotá, 30 de octubre de 1918c.

Gil Blas, Bogotá, 21 de octubre de 1918.

La Linterna, Tunja, 25 de octubre de 1918.

Sur América, Bogotá, 26 de octubre de 1918a.

Sur América, Bogotá, 29 de octubre de 1918b.

Sur América, Bogotá, 31 de octubre 1918c.

Sur América, Bogotá, 2 de noviembre de 1918d.

Sur América, Bogotá, 9 de noviembre de 1918e.

\section{Leyes}

Acuerdo 40/1918, 2 de noviembre, Concejo de Bogotá.

Ley 30/ 1886, de 20 de octubre, por el que se crea Juntas de Higiene en la Capital de la República y en las de los Departamentos y Ciudades principales.

Ley 84/1914, por la cual se dictan algunas disposiciones sobre extinción de la langosta y sobre higiene pública y privada.

Ley 46/1918, 19 de noviembre, Senado de Colombia, por la cual se dicta una medida de salubridad pública y se provee a la existencia de habitaciones higiénicas para la clase proletaria. 